\title{
Finding a Place for Genomics in Health Disparities Research
}

\author{
S.M. Fullerton S. Knerr W. Burke \\ Department of Bioethics and Humanities, and Center for Genomics and Healthcare Equality, University of \\ Washington, Seattle, Wash., USA
}

\author{
Key Words \\ Benefit $\cdot$ Bioethics $\cdot$ Genomics $\cdot$ Health care $\cdot$ Health \\ disparities $\cdot$ Research policy
}

\begin{abstract}
The existence of pronounced differences in health outcomes between US populations is a problem of moral significance and public health urgency. Pursuing research on genetic contributors to such disparities, despite striking data on the fundamental role of social factors, has been controversial. Still, advances in genomic science are providing an understanding of disease biology at a level of precision not previously possible. The potential for genomic strategies to help in addressing population-level disparities therefore needs to be carefully evaluated. Using 3 examples from current research, we argue that the best way to maximize the benefits of population-based genomic investigations, and mitigate potential harms, is to direct research away from the identification of genetic causes of disparities and instead focus on applying genomic methodologies to the development of clinical and public health tools with the potential to ameliorate healthcare inequities, direct population-level health interventions or inform public policy. Such a transformation will require close collaboration between transdisciplinary
\end{abstract}

teams and community members as well as a reorientation of current research objectives to better align genomic discovery efforts with public health priorities and well-recognized barriers to fair health care delivery.

Copyright $\odot 2012$ S. Karger AG, Basel

Significant and pervasive differences in disease incidence, prevalence, morbidity, and life expectancy persist between populations within the US $[1,2]$ as well as among nations globally [3]. Clearly, the existence of such pronounced differences in health outcome is a problem of moral significance and public health urgency. A large body of research has implicated an array of nongenetic contributors, including racial discrimination, low socioeconomic status, environmental hazards and exposures, psychosocial stress, reduced access to health care, poor doctor-patient communication, low levels of health literacy, and cultural factors $[4,5]$. The relative role that genetic factors play in group-level differences in health outcome has been more controversial $[5,6]$, despite recognition that interindividual differences in susceptibility can be relevant to health [7]. Nevertheless, there has been significant interest among genome scientists in investigating genetic contributions to population health differenc-

\section{KARGER}

Fax +4161306 1234

E-Mail karger@karger.ch

www.karger.com
(C) 2012 S. Karger AG, Basel

$1662-4246 / 12 / 0154-0156 \$ 38.00 / 0$

Accessible online at:

www.karger.com/phg
Stephanie M. Fullerton, $\mathrm{PhD}$

University of Washington

Department of Bioethics and Humanities, Box 357120

Seattle, WA 98195 (USA)

Tel. +1 206616 1864, E-Mail smfllrtn@uw.edu 
es, based on the assumption that genes could play a greater contributory role than public health experts expect [8-10]. Critiques of such research have focused largely on the potential harms associated with ascribing genetic predispositions to socially defined groups $[11,12]$. Others, however, have also questioned the presumed benefits of genetic research, suggesting that genomic discoveries are unlikely to have any significant effect on the elimination or reduction of disparities [13].

While this debate remains largely unsettled, the tools of genome science are playing an increasingly central role in biomedical research. There is good reason for an increasing focus on genomics in health-related investigation: genome-wide association studies and sequencing technologies are expediting gene discovery, and related molecular approaches (including gene expression and proteome studies) offer powerful new strategies for understanding disease biology at a level of precision not previously possible. Given their importance in current research, we argue that these research tools need to be carefully evaluated for their potential to help in addressing population health disparities, while giving due weight to the caveats of bioethicists and population health experts $[13,14]$.

To do this, we first consider what the near-term healthrelated benefits of genomic research are likely to be. Then, with the help of examples, we examine how these benefits might relate to the address of specific health disparities. As we will argue, the best way to maximize the benefits of population-based genomic investigation and mitigate the harms is to direct research away from the identification of genetic causes of health disparities and instead focus on applying genomic methodologies to the development of clinical and public health tools with the potential to ameliorate health care inequities, direct populationlevel health interventions or inform public policy. In other words, finding a place for genomics in health disparities research may be more a matter of refiguring the ultimate translational objectives of current research projects $[15,16]$ than identifying to what degree genes do or do not contribute to different disease outcomes in different communities.

\section{Health-Related Benefits of Genomic Research}

Building on the successful foundation of the Human Genome Project [17], the genome sciences are now expanding their clinical focus [10]. A trickle of clinical applications has begun to enter practice, and many more health-related benefits are anticipated.
First Benefit of Genomic Research: New Knowledge

We can predict with certainty that genomic research will provide new knowledge about the many health conditions for which disparities are seen. Over the past decade, dramatic progress has occurred in the identification of genetic contributors to both Mendelian diseases [18] and common complex diseases [19]. A few promising examples - e.g. research on inflammatory bowel disease $[20,21]$ - point to the potential for gene discovery to inform basic science, allowing for increasingly precise dissection of the molecular biology of complex diseases. In the case of inflammatory bowel disease, for example, gene discovery efforts have led to increased understanding of the role of several different biological pathways in disease etiology, helped to clarify overlap in different clinical conditions and offered hints about new therapeutic interventions [20]. This research effort can in turn lead to predictive testing and new insight into treatment.

\section{First Health Application: Genetic Testing}

As gene-disease associations are validated and extended to diverse populations, tests can be created for diagnosis or risk prediction, i.e. tests to direct specific treatment decisions. The most obvious benefits from this approach relate to Mendelian diseases; tests can provide definitive diagnoses, often offer prognostic information and, where treatments are available, contribute to clinical management. Progress has been particularly notable in cancer genetics. For example, genetic testing can identify individuals with inherited risk for breast and ovarian or colorectal cancer; screening and related interventions lead to cancer prevention and detection of cancers at earlier and more treatable stages [22,23]. Tests are also being developed to predict drug response [24] and risk for common complex diseases $[25,26]$. The scope of benefits from such tests is not yet clear, but some promising tests have already entered clinical practice. For example, several tests to guide drug use are now available [27]. One of the most promising is a test for an HLA variant that predicts the likelihood of adverse and potentially life-threatening skin reactions to abacavir, a reverse transcriptase inhibitor used in the treatment of HIV-AIDS [28]. An HLA variant can identify the minority of patients who are at risk for this reaction; the drug can be safely prescribed to those who do not have the variant. Another promising area is testing to refine disease classification. For example, gene expression profiling of early stage breast tumors provides information about likelihood of recurrence and can be used in chemotherapy decisions [29]. Testing can be used to identify those women who can safely avoid 
chemotherapy because of their low risk of recurrence, thus reducing the morbidity of treatment.

\section{Longer Term Hope: Improved Drug Development}

As genomic and related tools move toward an improved understanding of the molecular biology of disease, there is hope that this effort will open up new pathways to drug targets and molecules with therapeutic potential [30]. There are a few early examples that illustrate how genomics has assisted in novel drug development e.g. Herceptin as a targeted therapy based on genetic characteristics of breast tumor [31]; the development of imatinib followed by the rapid expansion of tools to explore the therapeutic potential of kinase inhibitors and tumor-specific proteins [e.g. 32, 33]. Intuitively, a more precise understanding of disease biology should open up a range of new therapeutic opportunities. Because this aspect of genomic discovery is still in its infancy, however, the scope of benefits is not yet known - nor is the extent to which new therapies will be targeted, e.g. providing benefit to a subcategory of patients identified by genetic testing, as opposed to treating patients based on signs or symptoms.

\section{Health Disparities-Related Benefits of Genomic Research}

As our brief review confirms, genomic research has considerable promise for improving individual health care. However, the potential for new genomic discoveries to reduce disparities or improve overall population health is less clear. Before considering specific examples which suggest promise for addressing health disparities, it is important to clarify two sets of related distinctions: (1) health versus health disparity, and (2) improving health care versus improving health.

\section{Health versus Health Disparity}

Most health conditions, including those that play a prominent role in population health disparities, are influenced by genetics. Understanding the genetics of a disease might lead to a better understanding of the problem, and from there to genetic tests to aid clinical care and possibly to new drugs or treatment strategies. These outcomes would have the potential to improve disease prevention and management, but none would necessarily affect health differences between populations. Type 2 diabetes mellitus (T2DM), for example, is more prevalent in African Americans, Native Americans, Hispanics and
Pacific Islanders, compared to European Americans, and is an important contributor to population differences in morbidity and mortality. Multiple genetic contributors to T2DM have been identified, and there is hope that such discoveries will provide health benefits [34]. Over time, research will clarify how genomic differences, likely in combination with myriad well-documented social and environmental factors [35, 36], contribute to risk for T2DM and its complications. While a number of potential benefits may result from this research (e.g. new pathways for drug development), these benefits may or may not yield insights into population disparities. Only when interventions address the root causes of population difference will they address the health disparity, as opposed to the health condition itself.

\section{Improving Health Care versus Improving Health}

If genomic observations lead to new tests or ideas for treatment, these could improve health care significantly. Given how limited and imperfect the management options are for many health conditions, including diabetes, this goal is an important focus for translational research [37]. However, from the perspective of overall population health, the delivery of clinical care is a relatively small factor $[38,39]$. Major advances in population health have largely come from public health interventions such as those to assure clean air, clean water and other improved living conditions. The main exceptions are in the areas of maternal health [40] and vaccination [41]. In considering the role of genomic research in addressing health disparities, therefore, the potential to inform population level is an important consideration even though the most immediate and obvious health benefits of genomic research are likely to apply to clinical care.

\section{Some Examples}

With these distinctions in mind, it is reasonable to ask whether new knowledge resulting from genomic research holds the potential to improve health outcomes specifically in individuals from populations experiencing health disparities, and as a result, decrease disparities. As long as social factors sustain disadvantage in access to benefits, such as health care, employment, education, and safe housing, even positive effects of genome-based therapeutics are likely to be modest at most $[42,43]$. To illustrate the challenges involved in shifting genomics toward a focus on reducing health disparities, we will walk through 3 examples of genomic research that hold promise for ad- 
dressing specific disparities but also have the potential to have minimal impact or widen existing gaps.

\section{Asthma}

One example that demonstrates the potential for genomic information to inform broad public health interventions comes from recent research highlighting the role of gene-environment interactions in childhood asthma [44]. In the US, African American and Puerto Rican children have disproportionally high rates of asthma morbidity and mortality compared to other racial and ethnic groups, though within all population groups poor and near-poor children have higher rates than those of higher socioeconomic status [45]. A number of environmental exposures have been implicated in asthma outcomes, including air quality [46]. A growing body of evidence also points to a contribution of genetic variation in pathways that detoxify reactive oxygen species present in air pollution to both asthma incidence and severity [47]. For example, individuals with deletions of glutathione-S-transferase $\mathrm{Mu} 1$ gene (GSTM1) have been observed to have higher sputum neutrophil and macrophage counts following ozone exposure as well as increased risk of asthma $[48,49]$. These negative outcomes are thought to occur because those with GSTM1 null mutations, which are present in almost half of the population in most ethnic groups, are unable to respond to oxidative stress [50,51].

Three potential pathways to health-benefit from such research are of particular interest. First, children with GSTM1 null mutations could be provided antioxidant supplementation via vitamins. There is preliminary evidence that such supplementation may help compensate for genetic susceptibility to ozone exposure and improve lung function [52, 53]. However, because the prevalence of the risk genotype does not track with health outcome disparities, this option may do little to remedy current disparities. Second, data on the increased risk conferred by GSTM1 null mutations, and their high prevalence in multiple populations, could be used to advocate for more stringent national air quality standards. This policy approach would decrease exposure to reactive oxygen species broadly [49]. Finally, algorithms that integrate both genotype and local air quality data could be used to identify families, apartment buildings, neighborhoods, or cities with increased asthma risk to target for home or employment-focused air quality interventions. Of the latter 2 pathways, the second option is most likely to generate health-disparities benefits, even though it does not intervene specifically on genetic risk. This is because African American and Puerto Rican children, as well as poor children of any racial and ethnic background, are more likely to live in areas with high rates of air pollution, for example, urban centers or near busy highways [54].

\section{Preterm Birth}

Another example where genomic information could hold potential involves the identification of genetic determinants of preterm birth. African American women have dramatically higher rates of preterm birth compared to other populations, though overall rates of preterm birth in the US are high [55]. The causes of this disparity, and the reasons for its persistence, are still unknown. Specific social and psychological risk factors have been identified, i.e. access to health care and perceived racism, but the disparity persists after controlling for these factors $[56,57]$. The growing focus on the contribution of genetic factors to the higher rates of preterm birth experienced by African American women $[58,59]$ is an area where increased knowledge of disease biology and geneenvironment interactions gained through genomic research may lead to the development of new and highly effective therapies.

Genetic research exploring determinants of preterm birth in African American women has identified several polymorphisms associated with increased risk, including variants in a currently undefined susceptibility locus on chromosome 7 [60], tumor necrosis factor alpha (TNF- $\alpha$ ) and tumor necrosis factor receptors 1 and 2 (TNFR1, TNFR2) [61], cytokines and cytokine-related genes [61], and in genes involved in infection and inflammation, including interleukin (IL)-12 and IL-12RB [62]. Though these observed genetic associations have been modest and for the most part unreplicated [55], they suggest that genetic variation contributing to variation in inflammation, maternal/fetal stress, uterine distension, decidual hemorrhage, and/or enzymatic metabolism may contribute to risk of preterm birth [59]. To the extent that genetic research can lead to a better understanding of these pathophysiologic pathways and the ways in which they interact with known social and environmental risk factors, new therapeutic options may result. Building on past experience in obstetric care, highly effective therapies that are informed by molecular biology but are also cheap and widely accessible could have the potential to help lower rates of preterm birth overall, i.e. health-benefit, but specifically for at-risk populations including African American women, i.e. health-disparities benefit. Innovative approaches would not replace the need to extend access to basic prenatal and perinatal care $[40,63]$, but could potentially provide added value. But, if the new therapies 
generated are inaccessible in resource-poor environments in which women at increased risk for preterm birth disproportionally reside, disparities will only increase.

\section{Chronic Kidney Disease}

Finally, recent identification of previously unrecognized genetic risk factors for distinct forms of chronic kidney disease has suggested promise for the address of kidney disease disparities. African Americans' cumulative lifetime risk of end-stage renal disease is approximately $7.5 \%$, while Caucasian Americans' is $2.1 \%$, with a disparity remaining after adjusting for socioeconomic status and lifestyle, as well as clinical factors [64]. Genetic variants associated with risk of numerous kidney disease phenotypes, including end-stage renal disease, were discovered in the gene encoding non-muscle myosin heavy chain type II isoform A (MYH9) [64, 65] and the adjacent apolipoprotein L1 gene (APOL1) [66]. Variants in the APOL1 gene appear to be most strongly associated with disease and apparently account for much of the racial disparity in rates of focal segmental glomerulosclerosis and hypertensive end-stage kidney disease. Moreover, a targeted role for genetic testing in clinical care has already been proposed, e.g. as a way to identify HIV-AIDs patients at greatest risk of renal failure [67, 68]. Specifically, genetic testing could be used to inform decisions about when to introduce antiretroviral therapy based on a patient's risk of HIV-related kidney disease based on APOL1 genotype as well as guide decisions about aggressiveness of potentially nephrotoxic therapies [68]. Genetic testing might also help to direct appropriate management of hypertension in individuals at increased risk for chronic renal failure [67-69].

However, caution is in order. The penetrance of the risk genotype appears to be very low [67]. As a corollary, other environmental, social or genetic factors may be important modifiers determining which individuals with the risk genotype will develop renal failure. From the perspective of disparity, a better understanding of the other factors contributing to renal failure in individuals with the APOL1 risk genotype may be critical in determining how genetics can best contribute to improved health outcomes. Testing to improve the management of individuals at risk - e.g. individuals with hypertension or other renal risk factors who are found to carry the risk genotype - may lead to measurable improvements in renal outcomes. But if the modifying factors include social or environmental factors amenable to public health action, the benefit could be much greater. Additionally, though variants in MYH9 and APOL1 occur at a higher frequen- cy in individuals of African ancestry, they do occur in other populations and are also associated with increased risk [70]. In fact, one study found that Hispanic Americans with $A P O L 1$ risk-variants had greater risk of endstage renal disease than African Americans [71]. To date, only a handful of studies have looked at MYH9 and $A P O L 1$ variants in non-African ancestry populations [68]. If this lack of diversity is not remedied before the introduction of testing into clinical care, it is likely that many individuals, when tested, will receive indeterminate or inaccurate information.

\section{Reaching for a Transformative Vision}

As the chosen examples illustrate, recent observations in the genome sciences show promise for elucidating genedisease associations and biological pathways of relevance to population health disparities. To transform these, and related, preliminary promising findings into clinical and public health interventions with maximum potential to address persistent health disparities, current research efforts must incorporate greater consideration of long-term translational objectives. Doing this well will require genome scientists to collaborate to unprecedented degrees with public health scientists, community health workers and members of affected communities in an effort to identify the feasible interventions that will best advance public health as well as treatment and prevention.

First, genome scientists must acknowledge strong evidence for the role of social and environmental determinants in many health outcome disparities and ask not whether genes play some additional role in risk predisposition, but rather how genomic information could be better used to direct population-scale health interventions. For example, GSTM1 population prevalence data noted above suggests potential with respect to broadly informing air quality standards. Such policy implications are significant because they suggest profitable avenues for future research. Specifically, rather than focusing on the identification of additional asthma susceptibility variants, efforts might be better spent in carefully dissecting gene expression changes in populations predominantly exposed to particular classes of pollutants, e.g. agrarian populations, urban populations, communities situated near refineries or airports, with the aim of identifying the types of particulate matter most relevant to disease risk. Or, research teams could synthesize local data on aggregate genetic susceptibility to advocate for state or countywide policy changes or develop interventions that target 
the family or neighborhood level, for example, providing air purifiers to homes with multiple genetically susceptible children [72]. The robust design of any such study would, of course, rest on close collaboration with environmental scientists and community partners.

Second, genome scientists must acknowledge the potential for genetic tests and targeted treatments to exacerbate existing health care disparities and strive, wherever possible, to produce knowledge that will be readily transferable to low-resource settings and simplify care and/or prevention. For the case of current work focused on genetic contributions to preterm birth, for example, it is imperative that resulting therapies not only be inexpensive and easily obtained (made available, perhaps, in nonclinical settings), but also nonstigmatizing and longacting, in order to maximize uptake by the women already recognized to be a greatest risk. Recognizing community-based realities from the earliest stages of the translational cycle may help better direct discovery, where any one of a number of promising candidate avenues of investigation are available for subsequent development. Such recognition can only be achieved by interacting with the health care providers and community health workers who know best how pertinent health outcome disparities are experienced.

\section{Conclusion}

Debates surrounding the role of genomics in health disparities research will persist as long as genomic research remains focused on explaining population health differences rather than on using genetic associations and tools to understand disease processes in ways that can inform the clinical care of disparity populations or, preferably, direct population-scale public health interventions. This need not entail any fundamental shift in research methodology - on-going technological advances in genotyping and next generation DNA sequencing will remain important to the generation of comprehensive, accurate and ultimately affordable genetic information. Rather, what is needed is a reorientation of current research objectives to better align genomic discovery efforts with public health priorities and already well-recognized barriers to fair health care delivery. This cannot be achieved in isolation, but will require the close collaboration of genome scientists, epidemiologists, health services researchers, clinicians, community members, and others situated at diverse positions along the translational cycle linking bench-side discovery science to clinical development and delivery and ultimately population-level health outcomes [73].

\section{Acknowledgements}

This work was supported by the Center for Genomics and Healthcare Equality (P50 HG003374), and the Biobehavioral Cancer Prevention and Control Training Program (R25 CA92408), at the University of Washington as well as the Partnership to Understand and Eliminate Disparate Outcomes for Latinas (P50 CA148143) at the Fred Hutchinson Cancer Research Center.

\section{References}

$>1$ Ezzati M, Friedman AB, Kulkarni SC, Murray CJ: The reversal of fortunes: trends in county mortality and cross-county mortality disparities in the United States. PLoS Med 2008;5:e66.

-2 Murray CJ, Kulkarni SC, Michaud C, Tomijima N, Bulzacchelli MT, Iandiorio TJ, Ezzati M: Eight Americas: investigating mortality disparities across races, counties, and race-counties in the United States. PLoS Med 2006;3:e260.

3 World Health Organization Social Determinants of Health (Final report): Closing the gap in a generation: health equity through action on the social determinants of health. 2008.

$\checkmark 4$ Dressler WW, Oths KS, Gravlee CC: Race and ethnicity in public health research: mod- els to explain health disparities. Annu Rev Anthropol 2005;34:231-252.

5 Fine MJ, Ibrahim SA, Thomas SB: The role of race and genetics in health disparities research. Am J Public Health 2005;95:21252128 .

6 Frank R: What to make of it? The (Re)emergence of a biological conceptualization of race in health disparities research. Soc Sci Med 2007;64:1977-1983.

7 Carter-Pokras O, Baquet C: What is a 'health disparity'? Public Health Rep 2002;117:426434.

$>8$ Bamshad M: Genetic influences on health: does race matter? JAMA 2005;294:937946.

-9 Burchard EG, Ziv E, Coyle N, Gomez SL, Tang H, Karter AJ, Mountain JL, Pérez-Sta- ble EJ, Sheppard D, Risch N: The importance of race and ethnic background in biomedical research and clinical practice. $\mathrm{N}$ Engl J Med 2003;348:1170-1175

10 Green ED, Guyer MS; National Human Genome Research Institute: Charting a course for genomic medicine from base pairs to bedside. Nature 2011;470:204-213.

11 Sankar P, Cho MK, Condit CM, Hunt LM, Koenig B, Marshall P, Lee SS, Spicer P: Genetic research and health disparities. JAMA 2004;291:2985-2989.

12 Shields AE, Fortun M, Hammonds EM, King PA, Lerman C, Rapp R, Sullivan PF: The use of race variables in genetic studies of complex traits and the goal of reducing health disparities: a transdisciplinary perspective. Am Psychol 2005;60:77-103. 
13 de Melo-Martin I: Genetic research and reduction of health disparities. N Genet Soc 2008;27:57-68.

$\checkmark 14$ Cooper RS, Kaufman JS, Ward R: Race and genomics. N Engl J Med 2003;348:11661170.

15 Burke W, Press N: What outcomes? Whose benefits? in Burke W, Edwards K, Goering S, Holland S, Trinidad SB (eds): Achieving Justice in Genomic Translation: Rethinking the Pathway to Benefit. New York, Oxford University Press, 2011, pp 162-176.

16 Fullerton SM: The input-output problem: whose DNA do we study, and why does it matter? in Burke W, Edwards K, Goering S, Holland S, Trinidad SB (eds): Achieving Justice in Genomic Translation: Rethinking the Pathway to Benefit. New York, Oxford University Press, 2011, pp 40-55.

-17 Lander ES, Linton LM, Birren B, Nusbaum $\mathrm{C}$, Zody $\mathrm{MC}$, et al: Initial sequencing and analysis of the human genome. Nature 2001 409:860-921.

18 Ng SB, Nickerson DA, Bamshad MJ, Shendure J: Massively parallel sequencing and rare disease. Hum Mol Genet 2010;19:R119124.

19 Manolio TA, Brooks LD, Collins FS: A HapMap harvest of insights into the genetics of common disease. J Clin Invest 2008;118: $1590-1605$

20 Cho JH: The genetics and immunopathogenesis of inflammatory bowel disease. Nat Rev Immunol 2008;8:458-466.

21 Imielinski M, Hakonarson H: Breaking new ground in inflammatory bowel disease genetics: genome-wide association studies and beyond. Pharmacogenomics 2010;11:663665.

22 Lindor NM, Petersen GM, Hadley DW, Kinney AY, Miesfeldt S, Lu KH, Lynch P, Burke W, Press N: Recommendations for the care of individuals with an inherited predisposition to Lynch syndrome: a systematic review. JAMA 2006;296:1507-1517.

23 Petrucelli N, Day MB, Feldman GL: BRCA1 and BRCA2 Hereditary Breast and Ovarian Cancer. GeneReviews 2011. http://www. ncbi.nlm.nih.gov/books/NBK1247/.

-24 Wang L, McLeod HL, Weinshilboum RM: Genomics and drug response. N Engl J Med 2011;364:1144-1153

-25 Holmes MV, Harrison S, Talmud PJ, Hingorani $\mathrm{AD}$, Humphries SE: Utility of genetic determinants of lipids and cardiovascular events in assessing risk. Nat Rev Cardiol 2011;8:207-221.

-26 Mihaescu R, Meigs J, Sijbrands E, Janssens AC: Genetic risk profiling for prediction of type 2 diabetes. PLoS Curr 2011;3:RRN1208.

$\checkmark 27$ Relling MV, Klein TE: CPIC: Clinical Pharmacogenetics Implementation Consortium of the Pharmacogenomics Research Network. Clin Pharmacol Ther 2011;89:464467.
28 Lai-Goldman M, Faruki H: Abacavir hypersensitivity: a model system for pharmacogenetic test adoption. Genet Med 2008;10:874878.

29 Harris L, Fritsche H, Mennel R, Norton L, Ravdin P, Taube S, Somerfield MR, Hayes DF, Bast RC Jr; American Society of Clinical Oncology: American Society of Clinical Oncology 2007 update of recommendations for the use of tumor markers in breast cancer. J Clin Oncol 2007;25:5287-5312.

30 Altshuler D, Daly MJ, Lander ES: Genetic mapping in human disease. Science 2008; 322:881-888

31 Callahan R, Hurvitz S: Human epidermal growth factor receptor-2-positive breast cancer: current management of early, advanced, and recurrent disease. Curr Opin Obstet Gynecol 2011;23:37-43.

32 Argiris K, Panethymitaki C, Tavassoli M: Naturally occurring, tumor-specific, therapeutic proteins. Exp Biol Med (Maywood) 2011;236:524-536.

33 Fang B, Haura EB, Smalley KS, Eschrich SA, Koomen JM: Methods for investigation of targeted kinase inhibitor therapy using chemical proteomics and phosphorylation profiling. Biochem Pharmacol 2010;80:739-747.

34 Travers ME, McCarthy MI: Type 2 diabetes and obesity: genomics and the clinic. Hum Genet 2011;130:41-58.

35 Danaei G, Rimm EB, Oza S, Kulkarni SC, Murray CJ, Ezzati M: The promise of prevention: the effects of four preventable risk factors on national life expectancy and life expectancy disparities by race and county in the United States. PLoS Med 2010; 7:e1000248.

36 Nolan CJ, Damm P, Prentki M: Type 2 diabetes across generations: from pathophysiology to prevention and management. Lancet 2011;378:169-181.

37 Collins FS: Reengineering translational science: the time is right. Sci Transl Med 2011; 3:90 cm 17.

38 Farley TA: Reforming health care or reforming health? Am J Pub Health 2009;99:588590 .

-39 Teutsch SM, Fielding JE: Comparative effectiveness-looking under the lamppost. JAMA 2011;305:2225-2226.

-40 Betrán AP, Wojdyla D, Posner SF, Gülmezoglu AM: National estimates for maternal mortality: an analysis based on the WHO systematic review of maternal mortality and morbidity. BMC Public Health 2005;5:131.

-41 Roush SW, Murphy TV: Historical comparisons of morbidity and mortality for vaccinepreventable diseases in the United States. JAMA 2007;298:2155-2163.

42 Link BG, Phelan J: Social conditions as fundamental causes of disease. J Health Soc Behav 1995;Spec No:80-94.

43 Institute of Medicine: Crossing the Quality Chasm: A New Health System for the 21st Century. Washington, National Academy Press, 2011.
44 London SJ, Romieu I: Gene by environment interaction in asthma. Annu Rev Public Health 2009;30:55-80.

45 Moorman JE, Zahran H, Truman BI, Molla MT; Centers for Disease Control and Prevention (CDC): Current asthma prevalence United States, 2006-2008. MMWR Surveill Summ 2011;60(suppl):84-86.

46 Gent JF, Triche EW, Holford TR, Belanger K, Bracken MB, Beckett WS, Leaderer BP: Association of low-level ozone and fine particles with respiratory symptoms in children with asthma. JAMA 2003;290:1859-1867.

47 Minelli C, Wei I, Sagoo G, Jarvis D, Shaheen $\mathrm{S}$, Burney P: Interactive effects of antioxidant genes and air pollution on respiratory function and airway disease: a HuGE review. Am J Epidemiol 2011;173:603-620.

-48 Alexis NE, Zhou H, Lay JC, Harris B, Hernandez ML, Lu TS, Bromberg PA, Diaz-Sanchez D, Devlin RB, Kleeberger SR, Peden DB: The glutathione-S-transferase $\mathrm{Mu} 1$ null genotype modulates ozone-induced airway inflammation in human subjects. J Allergy Clin Immunol 2009;124:1222-1228.e5.

49 Searing DA, Rabinovitch N: Environmental pollution and lung effects in children. Curr Opin Pediatr 2011;23:314-318.

50 Montero R, Araujo A, Carranza P, Mejía-Loza V, Serrano L, Albores A, Salinas JE, Camacho-Carranza R: Genotype frequencies of polymorphic GSTM1, GSTT1, and cytochrome P450 CYP1A1 in Mexicans. Hum Biol 2007;79:299-312.

51 Romieu I, Sienra-Monge JJ, Ramírez-Aguilar M, Moreno-Macías H, Reyes-Ruiz NI, Estela del Río-Navarro B, Hernández-Avila M, London SJ: Genetic polymorphism of GSTM1 and antioxidant supplementation influence lung function in relation to ozone exposure in asthmatic children in Mexico City. Thorax 2004;59:8-10.

52 Braskett M, Riedl MA: Novel antioxidant approaches to the treatment of upper airway inflammation. Curr Opin Allergy Clin Immunol 2010;10:34-41.

-53 Sienra-Monge JJ, Ramírez-Aguilar M, Moreno-Macías H, Reyes-Ruiz NI, Del Río-Navarro BE, Ruiz-Navarro MX, Hatch G, Crissman K, Slade R, Devlin RB, Romieu I: Antioxidant supplementation and nasal inflammatory responses among young asthmatics exposed to high levels of ozone. Clin Exp Immunol 2004;138:317-322.

54 Evans GW: The environment of childhood poverty. Am Psychol 2004;59:77-92.

55 Muglia LJ, Katz M: The enigma of spontaneous preterm birth. N Eng J Med 2010;362: 529-535.

56 Bryant AS, Worjoloh A, Caughey AB, Washington AE: Racial/ethnic disparities in obstetric outcomes and care: prevalence and determinants. Am J Obstet Gynecol 2010; 202:335-343. 
-57 Spong CY, Iams J, Goldenberg R, Hauck FR, Willinger M: Disparities in perinatal medicine: preterm birth, stillbirth, and infant mortality. Obstet Gynecol 2011;117:948955.

58 Anum EA, Springel EH, Shriver MD, Strauss JF 3rd: Genetic contributions to disparities in preterm birth. Pediatr Res 2009;65:1-9.

59 Dolan SM: Genetic and environmental contributions to racial disparities in preterm birth. Mt Sinai J Med 2010;77:160-165.

60 Manuck TA, Lai Y, Meis PJ, Sibai B, Spong CY, Rouse DJ, Iams JD, Caritis SN, O'Sullivan MJ, Wapner RJ, Mercer B, Ramin SM, Peaceman AM; Eunice Kennedy Shriver National Institute of Child Health and Human Development (NICHD) Maternal-Fetal Medicine Units Network (MFMU): Admixture mapping to identify spontaneous preterm birth susceptibility loci in African Americans. Obstet Gynecol 2011;117:1078-1084.

-61 Menon R, Fortunato SJ, Edwards DR, Williams SM: Association of genetic variants, ethnicity and preterm birth with amniotic fluid cytokine concentrations. Ann Hum Genet 2010;74:165-183.

62 Velez DR, Fortunato S, Thorsen P, Lombardi SJ, Williams SM, Menon R: Spontaneous preterm birth in African Americans is associated with infection and inflammatory response gene variants. Am J Obstet Gynecol 2009;200:209.e1-27.
63 Cantwell R, Clutton-Brock T, Cooper G, Dawson A, Drife J, Garrod D, Harper A, Hulbert D, Lucas S, McClure J, Millward-Sadler H, Neilson J, Nelson-Piercy C, Norman J, O'Herlihy C, Oates M, Shakespeare J, de Swiet M, Williamson C, Beale V, Knight M, Lennox C, Miller A, Parmar D, Rogers J, Springett A: Saving Mothers' Lives: Reviewing maternal deaths to make motherhood safer: 2006-2008. The Eighth Report of the Confidential Enquiries into Maternal Deaths in the United Kingdom. BJOG 2011;118(suppl 1):1-203.

64 Kopp JB, Smith MW, Nelson GW, Johnson RC, Freedman BI, Bowden DW, Oleksyk T, McKenzie LM, Kajiyama H, Ahuja TS, Berns JS, Briggs W, Cho ME, Dart RA, Kimmel PL, Korbet SM, Michel DM, Mokrzycki MH, Schelling JR, Simon E, Trachtman H, Vlahov $\mathrm{D}$, Winkler CA: $M Y H 9$ is a major-effect risk gene for focal segmental glomerulosclerosis. Nat Genet 2008;40:1175-1184.

65 Kao WH, Klag MJ, Meoni LA, Reich D, Berthier-Schaad Y, Li M, Coresh J, Patterson N, Tandon A, Powe NR, Fink NE, Sadler JH, Weir MR, Abboud HE, Adler SG, Divers J, Iyengar SK, Freedman BI, Kimmel PL, Knowler WC, Kohn OF, Kramp K, Leehey DJ, Nicholas SB, Pahl MV, Schelling JR, Sedor JR, Thornley-Brown D, Winkler CA, Smith MW, Parekh RS; Family Investigation of Nephropathy and Diabetes Research Group: MYH9 is associated with nondiabetic end-stage renal disease in African Americans. Nat Genet 2008;40:1185-1192.

- 66 Genovese G, Friedman DJ, Ross MD, Lecordier L, Uzureau P, Freedman BI, Bowden DW, Langefeld CD, Oleksyk TK, Uscinski Knob AL, Bernhardy AJ, Hicks PJ, Nelson GW, Vanhollebeke B, Winkler CA, Kopp JB, Pays E, Pollak MR: Association of trypanolytic ApoL1 variants with kidney disease in African Americans. Science 2010;329:841845.
67 Kopp JB, Winkler CA, Nelson GW: MYH9 genetic variants associated with glomerular disease: what is the role for genetic testing? Semin Nephrol 2010;30:409-417.

68 Rosset S, Tzur S, Behar DM, Wasser WG, Skorecki K: The population genetics of chronic kidney disease: insights from the MYH9-APOL1 locus. Nat Rev Nephrol 2011; 7:313-326.

69 Freedman BI, Sedor JR: Hypertension-associated kidney disease: perhaps no more. J Am Soc Nephrol 2008; 19:2047-2051.

70 O'Seaghdha CM, Parekh RS, Hwang SJ, Li M, Kottgen A, Coresh J, Yang Q, Fox CS, Kao WH: The MYH9/APOL1 region and chronic kidney disease in European-Americans. Hum Mol Genet 2011;20:2450-2456.

-71 Tzur S, Rosset S, Shemer R, Yudkovsky G Selig S, Tarekegn A, Bekele E, Bradman N, Wasser WG, Behar DM, Skorecki K: Missense mutations in the APOL1 gene are highly associated with end stage kidney disease risk previously attributed to the $\mathrm{MYH} 9$ gene. Hum Genet 2010;128:345-350.

72 McDonald E, Cook D, Newman T, Griffith L, Cox G, Guyatt G: Effect of air filtration systems on asthma: a systematic review of randomized trials. Chest 2002;122:15351542.

73 Burke W, Edwards K, Goering S, Holland S, Trinidad SB: Achieving Justice in Genomic Translation: Rethinking the Pathway to Benefit. New York, Oxford University Press, 2011. 